\title{
Review on Medicinal benefits of London Rocket or SisymbriumIrio in different contextual aspects
}

\author{
Madhurima Tiwari ${ }^{1}$, Prachi Bhargava ${ }^{2 *}$ \\ ${ }^{1} \mathrm{PhD}$ Scholar,Institute of Biosciences and Technology, ShriRamswaroop Memorial University, Lucknow- \\ Deva Road, Barabanki (U.P).. \\ ${ }^{2 *}$ Associate Professor, Institute of Agricultural Sciences and Technology, ShriRamswaroop Memorial \\ University, Lucknow-Deva Road, Barabanki (U.P).
}

prachi.bio@srmu.ac.in

\begin{abstract}
Several studies done throughout the world on 'SisymbriumIrio L', also known as 'London Rocket' or 'Khakshi' has established that this annual herb is of tremendous medicinal benefits. This review paper will focus on researches done using samples collected at widespread geographical range such as Jordan, Saudi Arabia, Kashmir, Rawalpindi, Lahore, Rajasthan, UK, Europe, Mediterranean Islands, North Americaand Caucasia among others. Further we will study about various phytochemicals produced by aerial parts, seeds and other partsofSisymbriumIrio L and their clinical uses which were discovered experimentally. Such as alkaloids of aerial parts for 'Liver Disease'; flavonoids, steroids and alkaloids in seeds as expectorant and stimulant for 'Clinical Asthma'; histamine aerosol for protection against 'Bronchospasm'; ethyl acetate, aqueous extracts and butanol from other parts as potential 'Nutraceutical Antioxidant'. Apart from these there is presence of various secondary metabolites such as flavonoids, triterpenoids or steroids, saponins, alkaloids, carbohydrates and tannins and absence of Anthraquinones and cardiac glycosides which were found to be of 'Chemotherapeutic Interest' . Hence we will analyze the overall effects of various phytochemicals produced from different parts of Sisymbriumirio L and further study the possibility to use this plant as potential replacement various commercially used Antibiotics.
\end{abstract}

\section{Inroduction}

In modern therapeutic system Antibiotics play significant role in controlling various diseases, mainly infectious ones. Antibiotics are widely available as well as popular tool for fighting with various physiological problem (Finland, 1978, Caldenwood et al., 1980). However growing popularity and careless use of such medications has led to advent of 'drug resistance' 
phenomenon. Also many antifungal and antibacterial agents are found to exhibit serious detrimental effects on host tissues leading to the toxicity in human system(Marr, 1982; Bolard et al., 1986). Due to these untowardeffects these medicines needs a suitable replacement.

There is a long history of 'Plant based therapies' in treating various ailments. This kind of therapies is comparatively harmless. Due to which modern researchers are all attracted in natural products for the purpose of treating various challenging diseases. There are some chemical components which produce a specific physiological action on human body that defines the actual medicinal value of plants. Some of these components are phenolic compound, tannis, flavonoids and alkaloids. There are several reports on plants use in traditional healing in tribal areas by indigenous communities. (Threlfall EJ et al.,1998).

Various researchers have found family 'Cruciferae' also known as Brassicaceae of many applications in both commercial as well as pharmaceutical aspects w.r.t important sources of oil or food products (Migahid et al., 1996). It has also found its application in folk medicine (ALMazroa et al., 2015). One of the cruciferae members named sisymbriumisusedin treatment of rheumatoid, voice disorder inflammation etc. (AL-Jaber et al., 2011). Few members also showed anti-microbial, antioxidant, analgesic and antipyretic activities. Researches done throughout the world revealed that this particular genus is characterized by presence of various metabolites such as, steroid, oil,anthraquinone, alkaloid and flavonoid(Bolus et al., 1983).

\section{OVERVIEW}

Unani Medicine or 'UnaniTibb' is basically a form of traditional medicine practiced in SouthAsian and Middle- East countries. It refers to a tradition of Graeco-Arabic medicine, which is based on the teachings of Roman physician Galen and Greek physician Hippocrates and was further developed into an full fleshed medical system in middle age era by Persian and Arabian physicians, such as IbnNafis, Al-Zahrawi,Rhazes or al-Razi, and Avicenna or Ibn-e- Sina

Sisymbriumirio L (Khakshi or London)is found in various parts of the world such as western Pakistan, Middle East, Saudi Arabia, Caucasia, North America, Europe, Mediterranean island and United Kingdom(Heneidy et al., 2004). In India it is found to exist in Delhi area, Northern Rajasthan, Siwalik range in Punjab, Jammu \& Kashmir, Western Uttar Pradesh and Lucknow (Khoshoo et al., 1996). Available literature revealed that leaves and seeds are used as antipyretic, analgesic, antibacterial, febrifuge, in fevers and expectorant in asthma(Ghazanfar et al., 1994). These findingswere advent while dealing with isolation of flavonoid and $\beta$-sitosterol derivative(AL-Gendy et al., 2004),(Gehan et al., 2009). This plant is a rich source of glucosinolates(Cole et al., 1976), (Griftiths et al., 2001) and flavonoids (Del-Pero-De et al., 1982),(Kahan et al., 1991).It can be used in salads and has sharp flavour. In folk medicine s. Irio $\mathrm{L}$ is used for infection of chestand throat, treatingasthma, as a febrifuge and a stimulating poultice, (Muhammad et al., 2000), liver detoxification, reducing swelling, cleaning wounds, chest congestion, treatment of coughs and rheumatism (Lev F et al., 2003). 


\section{Uses of sisymbriumIrio in Unani Therapy}

Sisymbriumirio Linn of the family 'Brassicaceae' is being used in Unani Medicine since long time as antipyretic-aphrodisiac-expectorant-analgesic-antimicrobial in fever, gastric ulcer,cough, pulmonary and urinary tract infections, skin disorders and liver complaints etc. Its widely mentioned that all the all of the parts are very much useful in traditional medicine but amongst all parts of Sisymbriumirio such as: stem, flowers, seeds, aerial parts \& leaves contains several phytochemicals such as 'tannin', 'alkaloids', 'flavonoids', 'saponins', 'glycosides', 'carbohydrates', 'phenolics', 'amino acids', 'proteins', 'steroids', 'fatty acids' responsible for various pharmacological actions such as antifungal, antimicrobial, pimples, cough, hepatoprotective, anticancer, anti-inflammatory, diuretic, antidepressant, bronchoprotective role, phytotoxic, expectorant, cytotoxic, voice disorders, rheumatoid, antipyretic, analgesic, febrifuge, detoxify liver \& spleen, stomachic treatmentsand boils. For the identification of the natural template for safer drug designing and discovery there is the necessity for qualitative screening with scientific approach.

\section{Compositional study}

Ma. Al-Qudah et al., in 2010 extracted and worked upon the essential oils found in SisymbriumIrio and detailed their composition and percentage of existence. The components of oil was analysed by Gas chromatography and mass spectrometry. Experimentations elaborated that oil contained fifty three components in total as mentioned in table 1

\begin{tabular}{llcc}
\hline No. & Compound & $\begin{array}{c}\text { Retention } \\
\text { time, min }\end{array}$ & Percentage \\
\hline $\mathbf{1}$ & Dotriacontane & 118.70 & 0.06 \\
\hline $\mathbf{2}$ & Octadecanal & 117.23 & 1.10 \\
\hline $\mathbf{3}$ & Squalene & 116.71 & 0.99 \\
\hline $\mathbf{4}$ & Heptacosane & 111.26 & 3.89 \\
\hline $\mathbf{5}$ & Nonacosane & 107.51 & 0.33 \\
\hline $\mathbf{6}$ & Docasanoic & 106.38 & 0.60 \\
\hline $\mathbf{7}$ & 1-Hexacosene & 105.87 & 0.40 \\
\hline
\end{tabular}




\begin{tabular}{|c|c|c|c|}
\hline 8 & Octacosane & 103.78 & 1.25 \\
\hline 9 & Dioctyladipate & 100.00 & 25.44 \\
\hline 10 & Eicosanoic acid & 98.57 & 0.15 \\
\hline 11 & Docasane & 95.86 & 0.36 \\
\hline 12 & Stearic acid & 90.21 & 2.07 \\
\hline 13 & 12-Methyl-E,E- 2,13-octadecadien-1-ol & 89.39 & 2.04 \\
\hline 14 & cis-8,11,14-Eicosatrienoic acid & 89.16 & 6.30 \\
\hline 15 & Palmitic acid & 81.34 & 3.45 \\
\hline 16 & Oleic acid & 76.56 & 0.67 \\
\hline 17 & 1-Eicosanol & 75.35 & 0.39 \\
\hline 18 & 3,7,11,15-Tetramethyl-2-hexadecen-1-ol & 74.96 & 6.52 \\
\hline 19 & 2,3,6-Trimethyl-1,4-naphthalenenedione & 70.25 & Trace \\
\hline 20 & $\begin{array}{l}\text { 2-(2-Methylpropylidene)-1H-indene-1,3(2H)- } \\
\text { dione }\end{array}$ & 70.23 & 0.08 \\
\hline 21 & 13-Heptadecyn-1-ol & 68.49 & 0.06 \\
\hline 22 & Methoxyeugenol & 67.71 & Trace \\
\hline 23 & $\begin{array}{l}\text { 4-(2,4,4-trimethyl-cyclohexa-1,5-dienyl)but-3- } \\
\text { en-2-one }\end{array}$ & 63.31 & 0.05 \\
\hline 24 & Tetrahydrospirilloxanthin & 62.60 & Trace \\
\hline 25 & $\begin{array}{l}\text { 5-Isopropenyl-2-methylcyclopent-1- } \\
\text { enecarboxaaldehyde }\end{array}$ & 62.16 & 0.16 \\
\hline 26 & 1,2-Dipalmitate glycerol & 61.84 & 0.07 \\
\hline
\end{tabular}




\begin{tabular}{|c|c|c|c|}
\hline 27 & Deoxysericealacone & 61.76 & Trace \\
\hline 28 & $\begin{array}{l}\text { 1,2,3b,6,7,8,-Hexahdro-6,6-dimethyl } \\
\text { cyclopenta[1,3]cyclopropa[1,2]cyclohepten- } \\
\text { 3(3H)-one }\end{array}$ & 60.75 & Trace \\
\hline 29 & $\begin{array}{l}\text { 8-Isopropyl-1,2,3,7-tetramethylbicyclo[5,1,0] } \\
\text { octa-5-en-2-one }\end{array}$ & 60.80 & 0.11 \\
\hline 30 & 3_,5_-Dimethoxyacetophenone & 60.20 & 2.54 \\
\hline 31 & Isovanillin & 49.88 & 0.13 \\
\hline 32 & 3-Methyl indole & 48.98 & 0.05 \\
\hline 33 & $o$-Benzyl- $L$-serine & 47.69 & 0.06 \\
\hline 34 & 1,1,6-Trimethyl-1,2,3,4-tetrahydronaphthalene & 47.13 & 0.11 \\
\hline 35 & 1,1,6-Trimethyl-1,2-dihydronaphthalene & 46.85 & Trace \\
\hline 36 & 1,5,8-Trimethyl-1,2-dihydronaphthalene & 46.84 & Trace \\
\hline 37 & Nicotine & 46.40 & 0.06 \\
\hline 38 & $p$-Vinylguaiacol & 44.47 & 0.78 \\
\hline 39 & Indole & 43.06 & 0.22 \\
\hline 40 & p-Anisaldehyde & 40.35 & 0.08 \\
\hline 41 & trans-Z-_-Bisabolene epoxide & 30.39 & 0.05 \\
\hline 42 & 4-(2,5-Dihydro-3-methoxy phenyl)butylamine & 30.37 & Trace \\
\hline 43 & Nonanal & 29.79 & 0.07 \\
\hline 44 & $\beta$-Terpinyl acetate & 23.56 & 0.12 \\
\hline
\end{tabular}




\begin{tabular}{|llcc|}
\hline $\mathbf{4 5}$ & 3E-Hexenoic acid & 22.80 & 0.05 \\
\hline $\mathbf{4 6}$ & Tetra acetyl-d-xylonic nitrile & 20.87 & Trace \\
\hline $\mathbf{4 7}$ & n- Butyl isothiocyanate & 15.69 & 2.85 \\
\hline $\mathbf{4 8}$ & Dimethyl sulphone & 14.92 & 0.10 \\
\hline $\mathbf{4 9}$ & 3-Hexen-1-ol & 10.11 & Trace \\
\hline $\mathbf{5 0}$ & 2E-Hexenal & 9.65 & Trace \\
\hline $\mathbf{5 1}$ & Isopropyl isothiocyanate & 8.34 & 11.55 \\
\hline $\mathbf{5 2}$ & Isobutyl isothiocyanate & 8.76 & 6.75 \\
\hline $\mathbf{5 3}$ & $N$-(n-propyl)acetamide & 8.50 & 14.77 \\
\hline
\end{tabular}

Table 1. Percentage and Composition of the essential oil extracted from Sisymbriumirio.

\section{Analysis of essential oil extracted from SisymbriumIrio}

These 53 components represented about $97.5 \%$ of the total oil. Further it was found that $38.80 \%$ was consisting of two Easters and seven acids, 36.41\% of eleven nitrogen and sulphur containing compounds, 15 terpenoids consist of about $8.2 \%$, 6.3\% of aliphatic hydrocarbons. $3.53 \%$ of aromatic compound, $2.5 \%$ of fatty acids and $1.17 \%$ of other components.

\section{Phytochemical Analysis of SisymbriumIrio}

The phytochemical screening of different extracts showed the presence of variety of important constituents such as carbohydrates, triterpenoids or steroids, alkaloids, saponins, flavonoids and tannins at different levels in different parts of SisymbriumIrio and the absence of anthraquinonesand cardiac glycosides as shown in Table 2 [Al- Mazroa et al.,2015; Al-Gendy et al.,2008; Khalil et al.,2017; Khalil et al.,2015; Khalil et al.,2016; Samy et al.,2015 Al-Jaber NA et al.,2011] 


\begin{tabular}{|c|c|c|c|c|c|c|c|c|c|}
\hline \multicolumn{2}{|c|}{ Plant organ } & \multirow{2}{*}{$\begin{array}{c}\text { Triterpenoids } \\
\text { steroids } \\
\text { A }\end{array}$} & \multirow{2}{*}{$\begin{array}{c}\text { Alkaloids } \\
\text { A }\end{array}$} & \multirow{2}{*}{$\begin{array}{c}\text { Flavonoids } \\
\text { P }\end{array}$} & \multirow{2}{*}{$\begin{array}{c}\text { Tannins } \\
\text { P }\end{array}$} & \multirow{2}{*}{$\begin{array}{c}\text { Carbohydrates } \\
\text { P }\end{array}$} & \multirow{2}{*}{$\begin{array}{c}\begin{array}{c}\text { Cardiac } \\
\text { glycosides }\end{array} \\
\text { A }\end{array}$} & \multirow{2}{*}{$\begin{array}{c}\text { Anthraquinones } \\
\text { A }\end{array}$} & \multirow{2}{*}{$\begin{array}{l}\text { Saponins } \\
\text { A }\end{array}$} \\
\hline \multirow{5}{*}{ Stems } & $A Q$ & & & & & & & & \\
\hline & BT & $P$ & $P$ & $P$ & $P$ & $P$ & $A$ & $A$ & $P$ \\
\hline & $\mathrm{CH}$ & $\mathbf{P}$ & $P$ & $\mathbf{P}$ & A & A & A & A & $\mathbf{P}$ \\
\hline & EA & $P$ & $P$ & $\mathbf{P}$ & $P$ & $P$ & A & A & $\mathbf{P}$ \\
\hline & $\mathrm{nH}$ & $\mathbf{P}$ & A & A & A & A & A & A & $\mathbf{P}$ \\
\hline \multirow{5}{*}{ Roots } & $A Q$ & A & A & $\mathbf{P}$ & $\mathbf{P}$ & $\mathbf{P}$ & A & A & A \\
\hline & BT & $P$ & $P$ & $P$ & $P$ & $P$ & A & A & $P$ \\
\hline & $\mathrm{CH}$ & $\mathbf{P}$ & $\mathbf{P}$ & $\mathbf{P}$ & A & A & A & A & $\mathbf{P}$ \\
\hline & EA & $P$ & $\mathbf{P}$ & $\mathbf{P}$ & $\mathbf{P}$ & $\mathbf{P}$ & A & A & $\mathbf{P}$ \\
\hline & $\mathrm{nH}$ & $P$ & A & $A$ & A & A & $A$ & $A$ & $P$ \\
\hline \multirow{5}{*}{ Leaves } & $A Q$ & A & A & $\mathbf{P}$ & $\mathbf{P}$ & $\mathbf{P}$ & A & A & A \\
\hline & BT & $\mathbf{P}$ & $\mathbf{P}$ & $\mathbf{P}$ & $\mathbf{P}$ & $\mathbf{P}$ & A & A & $\mathbf{P}$ \\
\hline & $\mathrm{CH}$ & $\mathbf{P}$ & $\mathbf{P}$ & $\mathbf{P}$ & A & A & A & A & $\mathbf{P}$ \\
\hline & EA & $P$ & $\mathbf{P}$ & $P$ & $P$ & $P$ & A & A & $P$ \\
\hline & $\mathrm{nH}$ & $P$ & A & A & A & A & A & A & $P$ \\
\hline \multirow{5}{*}{ flowers } & $A Q$ & A & A & $\mathbf{P}$ & $\mathbf{P}$ & $\mathbf{P}$ & $A$ & A & A \\
\hline & BT & $\mathbf{P}$ & $\mathbf{P}$ & $\mathbf{P}$ & $\mathbf{P}$ & $\mathbf{P}$ & A & A & $\mathbf{P}$ \\
\hline & $\mathrm{CH}$ & $\mathbf{P}$ & $\mathbf{P}$ & $\mathbf{P}$ & A & A & A & A & $\mathbf{P}$ \\
\hline & EA & $\mathbf{P}$ & $\mathbf{P}$ & $\mathbf{P}$ & $\mathbf{P}$ & $\mathbf{P}$ & A & A & $\mathbf{P}$ \\
\hline & $\mathrm{Nh}$ & $P$ & A & A & A & A & A & A & $P$ \\
\hline
\end{tabular}

Table2: Phytochemical screening w.r.t different fractions of major parts of SisymbriumIrio.

(Where specifications are as follows: AQ, Aqueous; BT, Butanol; EA, Ethyl acetate; CH, chloroform ; $n H$, n-Hexane.

' $A$ ' stands for Absence of a particular constituent whereas ' $P$ ' stands for Presence of a particular constituent.)

Study by above studies revealed that Sisymbriumirio L is characterized phytochemically by its contents of various chemical constituents as well as various parts extracts exhibited good 
antioxidant activities majorly aqueous fractions, butanol and ethyl acetate that attributes its higher contents of flavonoid and phenolic constituents. Hence above studies demonstrated the importance of leaves and stems when compared to flowers and roots. Studies identifies higher antioxidant activity therefore will a good source of herbal remedy[ Hany et al., 2017].

However according to researches done by Del Pero, De martinz in 1982, Griftiths,Deighton\& Nicholas in 2001, 'flavonoids' were found to be prominent in SisymbriumIrio. 'Gludosinolate' was proved to be present by the works of Cole in 1976. During previous studies on this plant isolation of quercetin, isorhamnetin, sitosteryl-D-glucoside and sitosterol was done by kahan, kalim\&kahan were performed in 1991.

For the first time 10 flavonoids were isolated from the Sisymbriumirio $\mathrm{L}$ frorm aerial parts during the research in Saudia Arabia. Chromatographic methods were used and the identification was done as luteolin-7-O-glucoside, apigenin, apigenin-7-O-b- D -glucoside, apigenin-7-diglucoside 5, apigenin7-O-(6 00 acetyl) glucoside, apigenin- 7-galactoside, apigenin 7 - O gluco 600-1 000 rhamnoside, apigenin-7-O-gluco (6 00 -1 000 ) rhamnoside 5 methoxide, kampferol3-xyloside-7-galactoside and kampferol .

Khan et al. in 1991, Itziar et al in1982 and Rizk et al., in 1986 in their respective studies found that this genus contained flavonoids [Lockwood and Fsharypuor, 1986] , anthraquinones , alkaloids, [Arayno and Zafor, 1983], oils, steroids

[Soulier, 1994] and glycosides [Krets et al in 1987].

Three flavonoids and two sitosterols were isolated from aerial parts of Sisymbriumirio L and seeds

[Khan et al in 1991]. It was reported that Sisymbriumirio L. could be used for dietary purposes. Due to the amount and diversity of protein (35\%) and nutrients content [Guil et al in 1998]. The ethanol extract from the seeds of Sisymbriumirio L. exhibited significant antipyretic and analgesic activities in addition to marked antibacterial action with no effect against fungi. Preliminary phytochemical screening of the plant revealed the presence of carbohydrates or glycosides, sterols and/or triterpenes, proteins and/or amino acids, coumarines, tannins, flavonoids, alkaloids and/or nitrogenous bases and saponins. Sisymbrium contains several classes of secondary metabolites such as flavonoids, alkaloids, anthraquinones, steroids and fatty acids [Al-Jaber, 2011; Al-Qudah and Abu Zarga, 2010; Vohoraet al in 1980]. It is well known that main volatile constituents of Brassicaceae plants, including genus Sisymbrium, are glucosinolate degradation products, mostly isothiocyanates (ITC) and nitriles, obtained by enzymatic and thermal degradation of glucosinolates. The plant is edible and rich in medicinally important bioactive metabolites e.g. flavonoids, phytosterols and unsaturated fatty acids. These facts make it highly nutritious component to integrate more frequently in our meals and also to be used in the production of health-promoting supplements.

\section{Therapeutic Applications of SisymbriumIrio}


Guil et al., in 2003 reported that SisymbriumIrio can be used for the treatment of rhematism and inflammation. It has antioxidant, antimicrobial as well as antipyretic potential (guil J et al., 1998) few other medical application and benefits found by various researches throughout the world are mentioned as below.

\begin{tabular}{|c|c|c|c|}
\hline & Parts of Sisymbriumlrio & Benefits & Studies \\
\hline \multirow{5}{*}{1.} & \multirow{4}{*}{$\begin{array}{l}\text { Seeds (shows insecticidal } \\
\text { phytotoxic and cytotoxic } \\
\text { activities according to Singh }\end{array}$} & Treatment of voice disorders & Meyer B et al., 1982 \\
\hline & & Expectorant and febrifuge & Ghazaufer S et al., 1994 \\
\hline & & $\begin{array}{l}\text { Treatment of rheumatoid and } \\
\text { inflammation }\end{array}$ & Bolus L et al., 1983 \\
\hline & & $\begin{array}{l}\text { Fewer, painkilling, antibacterial \& } \\
\text { antifungal activities }\end{array}$ & Verses et al., 1980 \\
\hline & & $\begin{array}{l}\text { Escharotic extracts showed anti- } \\
\text { inflammatory activity, broncho } \\
\text { protector role, swimstress } \\
\text { immobility and antidepressant role }\end{array}$ & $\begin{array}{l}\text { Sing RK } 2016 \\
\text { AL Mujalli et al., } 2013\end{array}$ \\
\hline \multirow{3}{*}{\multicolumn{2}{|c|}{ 2. Aerial parts }} & $\begin{array}{l}\text { Chest congestion, detoxification of } \\
\text { liver and Spleen, reduction of } \\
\text { swelling and wound cleaning }\end{array}$ & Rollem R et al., 1997 \\
\hline & & $\begin{array}{l}\text { Treatment of voice disorders, } \\
\text { expectorant }\end{array}$ & Schulz O et al., 1936 \\
\hline & & Inflammation and rheumatoid & Care T et al., 2017 \\
\hline
\end{tabular}




\begin{tabular}{|c|c|c|}
\hline & Antibiotic uses & Sumairash et al., 2013 \\
\hline 3. Seeds & $\begin{array}{l}\text { Treating disease caused by } \\
\text { bacterial strains }\end{array}$ & Shabnam B et al., 2015 \\
\hline \multirow{2}{*}{ 4. Leaves } & $\begin{array}{l}\text { Inhibiting growth of microbial } \\
\text { strains such as } \\
\text { styphloeccusepidermidis and } \\
\text { klebsiellapneumonia }\end{array}$ & Gamal M et al., 2017 \\
\hline & $\begin{array}{l}\text { Consumed as food and folk } \\
\text { medicine for infection of throat } \\
\text { and chest }\end{array}$ & AL- Juber et al., 2011 \\
\hline
\end{tabular}

Temesgen $\mathrm{H}$ et al., 2019 mentioned that the preexisting folk knowledge necessitates a scientific approach for a qualitative screening of plant (SisymbriumIrio L.) for identification of natural template for safer drug discovery as well as drug designing. They also found out that there are various phytochemicals present in different part of the plant which needs further biological and phytochemical investigation for developing novel drug molecules and discovering other therapeutic uses. Their reasoning was based on the fact that this plant is already used in Unani Medicine System for various therapeutic uses. It is recommended for the preservation of Dengue Fever as well due to presence of several bioactive compounds.

\section{Conclusion}

In this review paper we came across the presence of various secondary metabolites such as flavonoids, triterpenoids or steroids, saponins, alkaloids, carbohydrates and tannins and absence of Anthraquinones and cardiac glycosides which are found to be of 'Chemotherapeutic Interest' .We furtheranalysed the overall effects of various phytochemicals produced from different parts 
of Sisymbriumirio L and further studied. Presence of various phytochemicals in different part of the plant needs further biological and phytochemical investigation for developing novel drug molecules and discovering other therapeutic uses.

\section{REFERENCES}

Al-Gendy AA. Bull. Fac. Pharm. Cairo Univ. 2008; 46(2): 235-244

Al-Gendy AA. Bull. Fac. Pharm. Cairo Univ. 2008; 46(2): 235-244

Al-Jaber N, Phytochemical and biological studies of Sisymbriumirio L., Growing in Saudi Arabia, Journal of Saudi Chemical Society, 15 (2011) 345-350.

Al-Jaber NA. Journal of Saudi Chemical Society 2011; 15: 345-350.

Al-Jaber NA. Journal of Saudi Chemical Society 2011; 15: 345-350.

Al-Mazroa SA, Al-Wahaibi LH, Mousa AA, Al-Khathlan HZ. Arabian Journal of Chemistry 2015; 8: 212- 217.

Al-Mazroa SA, Al-Wahaibi LH, Mousa AA, Al-Khathlan HZ. Arabian Journal of Chemistry 2015; 8: 212-217.

Al-Mujalli A, Fouda T \& Hussein H, Effects of London rocket (Sisymbriumirio) on goats' health: Clinical and laboratory studies. Bulg. J. Vet. Med., 1 (2013) 48-52.

Bolus L. Medicinal plant of North Africa. Reference Publications Inc., 1983, p. 68.

BolusL, Medicinal plant of North Africa, Reference Publications, Inc: Chemical constituents of Sisymbriumirio L., from Jordan, Nat Prod Res. 24(5) (1983) 448-56.

Caldenwood S.B., Moellering R.C. (1980).Common adverse Effect of Antibacterial Agent on Major Organ System, Surg. Clin. N. Am., 60, 65-81.

Care E, Plant Taxonomy Prentice Hall, Inc., Englewood Cliffs, NJ, 1955, 321.

Cole R, Phytochemistry, 1976, 15, 759. 
Del-Pero-de M A, Martinez and Aguinagalde I, Parodiana, 1982, 1(2), 287.

Finland M;(1978). The New Development in Antibiotics, Ann. Intern. Med. 89, 849-853.

Gamal M, Saad A \& Mohammed H, Antimicrobial Activities and Cytotoxicity of Sisymbriumirio L., extract against Multi-Drug Resistant Bacteria (MDRB) \& Candida albicans. Int. J. Curr. Microbiol. App. Sci, 6(4) (2017) 1-13.

Gehan HA, Al-Gendy AA, El-Ayouty YM, Abdel-Motteleb A. Australian Journal of Basic and Applied Sciences. 2009; 3(3): 2097-2110.

Ghazanfar S, Handbook of Arabian medicinal plants, CRC Press, Boca Raton, Ann Arbor, London, Tokyo, 1994, 587.

Ghazanfar, SA. Handbook of Arabian Medicinal Plants. CRC Press, Boca Raton Ann Arbor, London,

Griftiths D, Deighton N \& Nicholas A, Identification of glucosinolate on the leaf surface of plants from the Cruciferae and other closely related species, Phytochemistry, 57 (2001) 693-700.

Griftiths D, Deighton N and Nicholas A, Phytochemistry, 2001, 57, 693.

Guil J, Guerrero J, Gimenez M \& Tarija M, Nutritional composition of wild edible Cruciferae species, J. Food Biochem, 23 (3) (1998) 283.

Heneidy SZ, Bidak LM. Pakistan Journal of Biological Sciences 2004; 7(6): 1010-1023.

Kahan M S, Kalim S and Kahan M, J Indian Chem Soc., 1991, 68, 532.

Khalil HE, Al Ahmed A. World Journal of Pharmaceutical Research 2017; 6(4):719-725.

Khalil HE, Aljeshi YM, Saleh FA, Mohamed TS. Journal of Chemical and Pharmaceutical Research 2017; 9(2): 210-215.

Khalil HE, Kamal MS. Journal of Pharmaceutical Sciences and Research 2015; 7(8): 509-513.

Kumara S, Sudipta K, Lokesh P, Neeki A, Rashmi P et al, Phytochemical screening and in vitro antimicrobial activity of Bougainvillea spectabilis flower extracts, Int. J. Phytomed, 4 (2012) 375-379.

Mahmoud A \& Musa H, Chemical constituents of Sisymbriumirio L., from Jordan, Natural Product Research, 5 (2010) 448-456.

Meyer B, Ferrigni N, Putnam J, Jacobsen L, Nichols D et al, Brine Shrimp: A convenient general bioassay for active plant constituents, PlantaMedica, 45 (1982) 31-34.

Migahid AM, Flora of Saudi Arabia, King Saud University, Riyadh, 1996. 
Rollins R, The Cruciferae of continental North America: Systematics of the mustard family from Arctic to Panama. Stanford University Press, Stanford, California, 1993, 97.

Samy MN, Khalil HE, Sugimoto S, Matsunami K, Otsuka H, Kamel MS. Journal of Pharmacognosy and Phytochemistry 2015; 4(1): 64-67.

Schulz O, Cruciferae, In: Engler, A, Prantl, K. (Eds.), Die NaturlichenPflanzenfamilien, Wilhelm Engelmann, Leipzig, 2 (1936) 227-658.

Shabnam B, Ziaur R, Khalid R \&Naveed I, Biological screening of polarity-based extracts of leaves and seeds of Sisymbriumirio L., Pak. J. Bot., 47 (2015) 301-305.

Singh RK, Acute toxicity, antiinflammatory and bronchial s mooth muscles investigation of Sisymbriumirio L., seeds in experimental animal models, International Journal of Research Studies in Biosciences, 1, (2015) 48-53.

Singh RK, Studies on ethanolic extract of Sisymbriumirio L, Seeds on in vitro rat mast cells, International Journal of Development Research, 6 (7)(2016) 8336-8338.

SumairaSh, Sirajud D, Rehmanullah\&Zahir M, Pharmacognostic standardization and pharmacological study of Sisymbriumirio L., American Journal of Research Communication, 1 (7) (2013) 241-253. Tokyo, 1994, p. 587.

Threlfall E. J., Frost JA., Ward L.R., and Rowe B.; (1996). Increasing spectrum of Resistance in Multi-resistant Salmonella typhimurium. Lancet, 347, 1053-1054.

Vohora S, Nagvi S \& Kumar H, Antipyretic analgesic and antimicrobial studies on SisymbriumirioL., Planta Med, 38 (1980) 255 